\title{
BEYOND BUDGETING: INOVAÇÃO OU RESGATE DE ANTIGOS CONCEITOS DO ORÇAMENTO EMPRESARIAL?
}

\section{RESUMO}

O estudo tem por objetivo analisar a abordagem conhecida pela expressão "beyond budgeting", que faz 0 questionamento do que é denominado abordagem "tradicional" do orçamento empresarial, e avaliar se ela constitui uma inovação. A estratégia do desenvolvimento do trabal ho é orientada por uma pesquisa bibliográfica, a partir da qual a análise se desenvolve. Esta trata as questões levantadas por críticos e confronta os clássicos do tema no sentido de tentar identificar possíveis inovações e novos problemas que possam derivar da nova abordagem. Em termos gerais, sugere-se que se trata de um novo ciclo que tenta recuperar os aspectos qualitativos clássicos do orçamento, que, uma vez cumpridos, não precisariam de um novo rótulo para serem administrativamente efetivos. Adicional mente, afirma-se que a abordagem, além de não resolver alguns problemas que a ausência do orçamento pode acarretar, cria outros que não existiriam sem a referida proposta.

\section{Fábio Frezatti}

USP

\begin{abstract}
This research analyzes the approach known as "beyond budgeting" and questions the "traditional" company budget approach, as well as evaluates whether it can be taken as an innovation. The development of this study was guided by a bibliographical research, which constituted the basis for a critical analysis. This analysis deals with the questions brought up by critics and confronts classical authors on the subject, in an attempt to identify possible innovations and new problems that may derive from the new approach. In general terms, it can be suggested that this new cycle tries to recover the classical qualitative aspects of budgeting, which, if fulfilled, would not require a new label to be managerially effective. Besides leaving unsolved a number of problems that may be entailed by the non-existence of a budget, the approach ends up creating other problems.
\end{abstract}

PALAVRAS-CHAVE Planejamento, orçamento tradicional, orçamento empresarial, beyond budgeting, processo orçamentário.

KEYWORDS Planning, traditional budget, company budget, beyond budgeting and budget process. 


\section{INTRODUÇÃO}

A reciclagem de um conceito é algo que pode acontecer ao longo dos tempos. Significa dizer que um conceito, depois de algum tempo, precisa ser repensado, revisado, al gumas vezes ampliado e, em al guns casos, esquecido. N um ambiente em que ocorrem mudanças com freqüência, em que 0 esgotamento de modelos e conceitos é comum, resistir à mudança simplesmente por rejeitar algo novo é um tipo de atitude que deve ser autopoliciada pelo pesquisador.

Aderir aos modismos também parece ser uma forma pouco responsável de o pesquisador se posicionar. $\mathrm{Na}$ dimensão de suas especificidades, os instrumentos gerenciais, compostos por vários conceitos, evoluem. As tecnologias se sucedem e a demanda por instrumentos mais adequados se apresenta como forte elemento de pressão sobre os gestores no sentido de diminuir a incerteza (Scapens, 1994; Otley, 1994). Em al guns casos isso acontece porque a proposta conceitual já não atende plenamente uma dada demanda. Podem ser citadas, por exemplo, a evolução da contabilidade no tratamento do capital intelectual e da ecologia.

Podem ser encontrados também exemplos de abordagens que foram apresentadas à comunidade e que, claramente, decorrem muito mais do refino de conceitos, métodos e modelos já existentes do que de uma ruptura significativa ou uma real novidade. São exemplos disso, o Economic Value Added (EVA), o Activity Based Management (ABM) e o Balanced Scorecard (BSC). Quer dizer que mudan ças significativas na gestão das atividades podem ser demandadas ou mesmo oferecidas a partir de mudanças nos recursos - particularmente de tecnologia de informação -, na forma de comportamento das pessoas nas organizações, e mesmo modelagens e ferramentas. Em muitos casos, trata-se de uma evolução significativa, com contribuições para o apoio aos gestores. Isso aconteceu com a área de gestão como um todo.

Podem ser encontrados modismos e verdadeiros projetos de marketing conceitual para proporcionar uma vertente financeiramente interessante aos negócios das consultorias, gerando nos pesquisadores uma sensação estranha devido ao descompasso entre a pesquisa, a aplicação e a mensuração de resultados de maneira metodologicamente aceitável. Dessa forma, a convivência entre o ceticismo e, em alguns casos, a má vontade de alguns pesquisadores em termos de mudanças e novas visões colide com aquela encontrada pelo consumidor ávido que, com freqüência, aceita instantaneamente as novidades sem questionar ou mesmo se perguntar se a relação custo-benefício é adequada. Ambas as posturas são igualmente perigosas para o progresso do conhecimento.

No campo da Administração, as particularidades encontradas no planejamento empresarial, com seus desdobramentos, são evidentes, passando-se pela evolução do planejamento estratégico e da própria estratégia, por exemplo. Esses artefatos interagem e se complementam a partir de uma rel ação hierárquica. N esse sentido, o processo orçamentário, claramente subordinado à elaboração da visão estratégica, durante muito tempo foi apresentado como al go extremamente objetivo e recomendado como fundamental ao controle da organização.

Welsch, Hilton e Gordon (1988, p. 50-52) discutem e defendem a possibilidade de dispor do orçamento de maneira formal - versus a informal -, e identificam razões para que ele seja formalizado e exista na empresa. Primeiro, o fato de que o processo de gestão não pode ser completamente desenvolvido de maneira al eatória, o que implica que o planejamento e o controle deveriam ser desenvolvidos de maneira lógica, consistente e sistemática; segundo, considerando que, ao existir um grande número de pessoas envolvidas no processo de gestão, o ambiente deve ser caracterizado com razoável nível de estabilidade e consistência para que as pessoas possam ter credibilidade; terceiro, objetivos, planos e metas não escritos em termos de prováveis resultados futuros impactam a empresa, freqüentemente tornando vaga e de difícil comunicação os "meios pensamentos" ou rumores de um ou mais indivíduos; quarto, a efetiva comunicação e o entendimento mútuo exigem certo nível de formalização; quinto, a formalização exige o estabelecimento e a observância de cronograma para decisões, implementações e controles; e, sexto, a formalização provê a base lógica para o racional, o significativo e a consistente flexibilidade na implementação do planejamento e do controle.

Com o passar do tempo, algumas críticas foram apresentadas, e pôde-se perceber que representam distintos níveis e graus de complexidade. Dentre as críticas identificadas, foram privilegiadas, ao longo deste trabalho, a menção de que o processo orçamentário é muito desgastante, muito custoso, adicionando pouco valor aos usuários; sua desconexão com o ambiente competitivo; e o fato de a informação econômica encorajar o comportamento disfuncional e não ético (Hope e Fraser, 2003, p. 197). 
Hope e Fraser (2003) reconhecem que os problemas por eles mencionados constituem problemas de execução e não de estratégia. Também aceitam que 0 orçamento pode ser desenvolvido em diferentes níveis de partici pação e enten dem que o instrumento permite aos executivos manter o controle sobre as divisões e unidades de negócios. Contudo, mencionam que, em mãos erradas, os contratos proporcionam resultados indesejáveis e disfuncionais em todos os níveis da organização. Afirmam que nem toda a culpa pode ser atribuída ao processo orçamentário, mas sim ao seu uso. Entretanto, consideram que o processo orçamentário possui semelhanças com um vírus, que trará conseqüências nocivas para a organização.

Visando atender às críticas em termos de utilidade do instrumento, a abordagem conhecida como beyond budgeting é apresentada como al ternativa adequada para os problemas mencionados. Ela é bastante agressiva e crítica, chegando a pregar a eliminação do orçamento anual das entidades. Levando em conta a efetiva discussão do tema, a questão que orienta este estudo é a seguinte: a visão do beyond budgeting traria novas contribuições ao planejamento empresarial tradicional ou apenas estaria rediscutindo antigas abordagens que estariam sendo aplicadas de maneira inadequada?

Dessa forma, este trabal ho tem por objetivo analisar os conceitos clássicos disponíveis, as críticas e as propostas, buscando aval iar se a abordagem do beyond budgeting proporciona inovação. A análise crítica foi orientada por pesquisa bibliográfica, considerada como adequada à necessidade do trabalho. Em termos de apresentação, o trabal ho segue o seguinte roteiro: identifica os conceitos relevantes referentes ao orçamento empresarial "tradicional"; distingue as causas dos problemas encontrados pelos autores que contestam 0 orçamento; apresenta o histórico e, em termos gerais, a proposta pertinente ao beyond budgeting; identifica os benefícios do beyond budgeting; confronta as abordagens; e apresenta as conclusões e considerações finais.

\section{O PROCESSO DE PLANEJAMENTO "TRADICIONAL"}

Revisitar os clássicos para a revisão da literatura é um exercício precioso que pode restaurar crenças e gerar percepções inéditas numa segunda ou terceira leitura, dados os diferentes graus de maturidade do leitor. As abordagens possíveis são diversas, mas os elementos a considerar serão descritos de maneira a incluir diferentes perspectivas de forma complementar.

Welsch, Hilton e Gordon (1988) definem "planejamento e controle abrangente de resultados", também denominado por Steiner (1979) "plano de negócios" - denominação atualmente utilizada mais freqüentemente para outra aplicação mais específica -, como sendo a abordagem sistemática e formalizada para desempenhar fases significativas das funções de planejamento e controle. Tal instrumento envolve o desenvolvimento e a aplicação de objetivos de longo prazo para a empresa, a especificação dos objetivos da empresa, um plano de longo prazo desenvolvido em termos gerais e um plano de curto prazo descrito com 0 objetivo de acompanhar as responsabilidades.

Esses autores consideram que a proposta básica do controle consiste em assegurar que os objetivos, metas e padrões da empresa sejam atingidos. Os planos de longo prazo proporcionam a visão financeira e numérica em relação à qual as estratégias possam afetar os resultados da organização. N esse momento surge 0 orçamento anual, que deve implementar as decisões tomadas no plano estratégico da organização. Em outras palavras, o orçamento cumpre um papel no processo de planejamento da organização ligado aos estilos de execução. 0 que está sendo proposto pelos autores é romper com o processo, eliminando a etapa do orçamento anual e, conseqüentemente, do controle orçamentário.

0 relacionamento - que deve ser seqüencial (Steiner, 1979) e harmônico (Welsch, Hilton e Gordon, 1988) entre o planejamento estratégico e o orçamento - é um fenômeno estrutural do processo, tratado na literatura. Entretanto, o grau de intensidade dos esforços despendidos pela organização na etapa estratégica e na etapa tática depende da formatação do modelo decisório, moldado às necessidades de cada organização.

Com o intuito de definir alguns termos utilizados neste trabal ho, deve-se considerar acerca do orçamento e do forecast:

- Hope eFraser (2003) entendem que o orçamento constitui muito mais um processo de desempenho gerencial do que de planejamento financeiro. Definem orçamento como sendo um plano expresso em termos financeiros que serve de base para o controle de desempenho, a alocação de recursos, o encaminhamento dos gastos e 0 compromisso com os resultados financeiros;

- "forecast" é definido por Hope e Fraser (2003) como sendo o resultado financeiro mais provável e os gastos relacionados ao negócio ou projeto por um período 
específico de tempo. A diferença em relação ao orçamento é a ausência do compromisso de atingir as metas, parte fundamental do conceito de orçamento;

- Hansen e Mowen (1996) mencionam que o orçamento constitui um plano financeiro abrangente para a organização e traz vários benefícios: força os gestores a planejar, proporciona recursos de informação que podem ser usados para aperfeiçoar o processo decisório, apóia o uso de recursos definindo um padrão que será, na seqüência, usado na aval iação de desempenho, e aperfeiçoa a comunicação e coordenação;

- Steiner (1979) observa a questão do planejamento dizendo que nenhuma empresa lucrou algo fazendo planos, pois o lucro vem da implementação dos planos. N esse sentido, referindo-se ao orçamento, diz que são métodos integrados para traduzir o plano estratégico em ações correntes, guiá-lo para a ação, definir padrões para a coordenação das ações e gerar a base para o controle de desempenho, que deve estar em conformidade com os planos, incluindo no processo: o planejamento, a coordenação e o controle. Para tanto, o sistema orçamentário tem que ser adaptado às peculiaridades de uma organização e deve ser desenvolvido para aperfeiçoar o processo de planejamento, já que força os gestores a focar suas atenções na formulação de objetivos e na forma como são implementados. Por outro lado, os orçamentos requerem especificações sobre o que significa atingi-los.

\section{LIMITACÕES E DEFICIÊNCIAS DO ORÇAMENTO EMPRESARIAL TRADICIONAL}

Com o objetivo de propiciar uma visão ampla e também pluralista do tema, relacionaram-se vários autores com diversas abordagens. Hansen, Otley e Van der Stede (2003) analisaram o orçamento da perspectiva da pesquisa e perceberam que as tendências podem ser agrupadas em abordagens mutuamente excludentes, ambas originárias de uma mesma organização, 0 Consortium for Advanced Manufacturing International (CAM-I). A primeira abordagem está relacionada ao grupo que defende a melhoria do processo orçamentário. Esse grupo considera que 0 activitybased budgeting deve ser a ferramenta que pode proporcionar esse benefício necessário para revitalizar o processo, a partir de foco no plano operacional. A segunda abordagem está relacionada ao grupo que defende 0 abandono do orçamento e, como seqüência, que seja desenvolvida uma radical descentralização da entidade. A abordagem desse grupo ficou conhecida como beyond budgeting.

No sentido de aperfeiçoar o processo, os autores recomendam que se desenvolvam al gumas ações, como revisões mais freqüentes do orçamento - inclusive utilizando o rolling-budgeting, incentivos à utilização do activity-based budgeting e foco na análise de desempenho mais voltado para os indicadores relativos e não os fixos. Welsch, Hilton e Gordon (1988) argumentam pelas limitações do orçamento e recomendam que seja formal izado e adotado pela empresa. N esse caso as estimativas que serviram de base devem ser continuamente adaptadas às circunstâncias; a execução do orçamento não ocorre virtualmente e o plano não se refere aos gestores.

Hansen e Mowen (1996) reconhecem que o orçamento tem grande impacto sobre o desenvolvimento da carreira, premiações e promoções dos executivos. Dessa maneira, o orçamento pode ter impacto sobre 0 comportamento dos participantes, sendo considerado comportamento positivo quando os objetivos do indivíduo estão alinhados com os objetivos da organização, o que é denominado congruência de objetivos. Contudo, quando inadequadamente administrado, as reações podem ser negativas sob inúmeros aspectos, culminando num comportamento disfuncional, o que significa comportamento individual que conflita com a organização, levantando questões de ética. Os problemas mais críticos são as definições de metas muito altas ou muito baixas. Metas desafiadoras mas exeqüíveis são um desafio permanente e saudável para os gestores. Outra dificuldade é superestimar custos ou subestimar receitas, criando reservas no orçamento, o que torna a exigência por desempenho menos objetiva. Ainda temos o problema de uma pseu doparticipação, caracterizada pela superficialidade, e que objetiva apenas ter a adesão formal dos subordinados às metas. Ademais, podemos encontrar ações que reduzem ou minimizam tais disfunções, como realimentação sobre o desempenho, incentivos monetários e não monetários, participação, padrões realísticos, controlabilidade de custos e múltiplas medidas de desempenho.

De acordo com Hope (2000), o orçamento tradicional possui algumas imperfeições, dentre as quais: a centralização por meio do sistema de orçamento, que passa pela ênfase na coerção e não pela coordenação relevantemente devida; o foco na redução de custos e não na criação de valor; restrição de iniciativas; manutenção do planejamento e sua execução separadas, 
em vez de próximas; problemas na al ocação de custos, ditos como não negociáveis; e centralização por parte da média gerência.

Hope e Fraser (2003) complementam as críticas ao que denominam processo tradicional de orçamento ao enfatizarem que ele proporciona baixo valor, conduz as pessoas a apresentarem comportamentos disfuncionais, com pouca atenção às variáveis fundamentais da competitividade, pressupondo falta de confiança. Para Fisher (2002), os pontos frágeis do processo tradicional podem ser descritos como perda de tempo, já que as pessoas gastam tempo no acompanhamento orçamentário falando sobre o passado - 0 que aconteceu versus o planejado -, enquanto o mais importante é discutir o futuro. Evidentemente 0 autor desconsidera que o processo de acompanhamento orçamentário pretende exatamente o compromisso quanto ao futuro. Adicionalmente, o processo orçamentário não encoraja as pessoas ao desempenho, mas ao desempenho do orçamento, e, finalmente, a revisão do orçamento é demorada e as empresas não conseguem fazê-lo rapidamente.

Horngren, Foster e Datar (2000) destacam os aspectos citados anteriormente de inadequada utilização do instrumento, considerando que a sub e superestimação permitem dispor de metas relativamente mais fáceis de serem alcançadas. Alternativamente, oferecem a visão do Kaizen budgeting, que incorpora as melhorias contínuas verificadas durante o período de planejamento.

Portanto, temos críticas de várias ordens, tanto se referindo às limitações do instrumento quanto às distorções a ele atribuídas. Dessa forma, o aparecimento da abordagem beyond budgeting poderia ser considerado previsível, dado o largo intervalo de tempo em que os questionamentos não encontraram eco no ambiente acadêmico.

\section{PRINCIPAIS PROBLEMAS VERIFICADOS COM O ORÇAMENTO}

Hope e Fraser (2003) identificam três causas principais para os problemas apontados anteriormente. A primeira diz respeito à dificuldade da elaboração e aplicação do orçamento, tornando-o demasiadamente caro. No entender dos autores, o processo é longo e envolve o tempo de muitos executivos de várias áreas da empresa. Algumas empresas tentaram apurar o custo de elaboração do instrumento, e os números são exor- bitantes. Por exemplo, a Ford M otor Company informou que gasta cerca de US $\$ 1,2$ bilhão por ano com a el aboração e a utilização do orçamento.

A segunda causa está relacionada à defasagem entre 0 orçamento e 0 ambiente altamente competitivo, não permitindo que se atendam às necessidades dos executivos ou gestores operacionais. No passado, os participantes focavam os processos gerenciais quase que exclusivamente a partir de metas de retorno sobre o capital, e implementavam planos para atingi-las. Dessa maneira, controles rígidos geravam desempenho de acordo com o planejado, proporcionando planejamento, coordenação e controle a partir do corporate center, 0 que tornava o orçamento adequado a esse propósito.

Os traços mais importantes da época foram a demanda dos acionistas por mel horias incrementais, ênfase no capital financeiro, inovação estável, os preços refletindo os custos, a lealdade dos clientes, e os investidores e reguladores ignorando padrões éticos. Por sua vez, os traços mais importantes vivenciados atualmente são: os acionistas demandando o melhor desempenho da sua classe; capital intelectual dominante; inovação rápida; a globalização derrubando preços; clientes voláteis; e os investidores e reguladores demandando padrões éticos. Algumas entidades responderam à demanda com planejamento mais enfatizado e freqüente, instrumentalizado por rolling budgets, e orçamentos elaborados a cada trimestre ou semestre, provocando trabalho adicional e aumento dos custos desse processo.

A utilização do Balanced Scorecard é a alternativa encontrada para manter a abordagem focada na estratégia, em lugar de mantê-la focada no orçamento. Hope e Fraser (2003) argumentam que, ainda assim, os indicadores se concentram no orçamento, voltados para o curto prazo. Os autores utilizam uma pesquisa de 2002 para afirmar que a maior parte dos indicadores são financeiros. Finalmente, indicam que o modus operandi do Balanced Scorecard é semelhante ao do orçamento tradicional, apurando variações.

A terceira causa diz respeito à extensão da manipulação de números, que atingiu níveis inaceitáveis. 0 início da utilização do orçamento em organizações Iucrativas se deu na década de 1920, quando al gumas empresas industriais - Du Pont, General Motors, ICI e Siemens - inauguraram a sua prática. $\mathrm{Na}$ década de 1960 foi introduzida a visão referente ao que Hope e Fraser (2003) denominaram "contratos fixos", ou seja, metas que seriam válidas para o exercício orçado. $\mathrm{Na}$ década de 1970 percebeu-se uma crescente dominação da contabilidade no sentido do controle dos resul- 
tados, com a conseqüente desatenção para atividades de produção, tecnologia e determinantes da competitividade do mercado. Adicionalmente, a própria educação executiva enfatizava a gestão por meio de números contábeis. Tudo isso levou a um aumento do uso de contratos fixos, a partir do compromisso do chefe com o subordinado. 0 contrato leva em conta a meta fixada, o incentivo ou premiação, um processo de aceitação do plano que percorre toda a organização a partir da negociação entre chefe e subordinado, comprometimento das ações interáreas e cronograma de relatórios.

Há comentários financeiros que afetam a análise dos autores sob diferentes aspectos. Pode-se dizer que 0 orçamento foi "seqüestrado" pelos profissionais da engenharia financeira, que o utilizam como controle remoto para o gerenciamento por números (Hope e Fraser, 2003, p. xviii). Tentou-se justificar casos como os da Enron e da WorldC om como decorrência da utilização do orçamento. Veja-se a declaração do antigo presidente da Enron: "Você tem um orçamento, e pode obter resultados cerca de $2 \%$ abaixo do orçamento. N ada além disso é aceitável" (Hope e Fraser, 2003, p. 12). Dessa maneira, argumentam esses autores, o orçamento leva os executivos a praticarem fraudes ou a se entregarem à prática de "jogos orçamentários".

A pós essa análise, os autores sugerem que um sadio processo de gestão deve permitir que se atendam aos objetivos mais importantes relacionados aos acionistas, se mantenham os melhores colaboradores, se inove, e se opere com baixo custo para satisfazer a lucratividade, mantendo uma governança efetiva e ética.

\section{BEYOND BUDGETING: BREVE HISTÓRICO E DEFINIÇÃ̃O}

Hope e Fraser (2003) citam o caso de Jan Wallander, CEO da Svenska H andelsbanken, conhecida instituição européia que havia abandonado há al gum tempo o modelo dito "tradicional" de planejamento central. De acordo com os autores, a empresa abandonou o orçamento em 1972 devido aos descontentamentos com os efeitos indesejáveis por ele provocados. Outro exemplo é a empresa Rodhia, multinacional francesa que abandonou o orçamento em 1999, depois que a Borealis, uma empresa dinamarquesa, fez o mesmo em 1995.

Recentemente, Wallander apresentou uma abordagem - reconhecida na literatura pela expressão beyond budgeting - que serve para caracterizar o processo de gestão flexível, sem a existência de um orçamento anual de resultados. Essa abordagem foi aplicada pelo banco escandinavo Svenska Handelsbanken, que obteve êxito gerenciando seus negócios por mais de 25 anos com resultados positivos, embora não superiores à concorrência (Hope, 2000).

0 esforço estruturado para trazer respostas à insatisfação em relação ao orçamento, considerado um instrumento rígido, teve seu início num grupo de executivos de organizações com atuações em empresas multinacionais, apoiados por consultores. As reuniões, realizadas a partir de 1997, geraram uma pesquisa realizada num grupo diversificado de empresas, em termos de setores e nacional idade (Hope e Fraser, 2003). 0 foco do estudo estava baseado nas seguintes questões: a) existe alguma al ternativa para o orçamento?; b) existe algum modelo gerencial?; c) que lições podem ser tiradas da implementação?

0 encaminhamento dessa reunião culminou na abordagem conhecida hoje como beyond budgeting, que se propõe especificar a formatação de gestão sem a existência do orçamento anual nas organizações. Ela se baseia na idéia de que deva existir fl exibilidade para os gestores, o que é obtido a partir de negociações, grande participação dos profissionais da "linha de frente", fazen do com que o planejamento e a execução sejam desenvolvidos pelos mesmos atores. A liderança de Hope e Fraser é percebida por meio de livros, artigos, de um site, e mesmo por meio de organizações empresariais que divulgam a beyond budgeting.

De acordo com esses autores, a abordagem beyond budgeting é um "grupo de processos alternativos que apóiam metas e reconhecimentos, um planejamento contínuo, a demanda de recursos, a coordenação dinâmica da empresa e um significativo grupo de controles nos vários níveis" (Hope e Fraser, 2003, p. xix). $\mathrm{Não}$ exige um processo anual de negociação que culmine com uma meta fixa, e exige mai or confiança entre os participantes, focan do a relação entre os executivos seniores e a gerência da entidade.

Os ingredientes tratados nessa abordagem são os seguintes (Hope e Fraser, 2003, p. 70):

- definição de metas levando em conta benchmarking externo à organização, numa perspectiva de médio prazo. Não existem metas fixas, mas variáveis, decorrentes do momento vivenciado pelos gestores. Pretende eliminar as metas anuais fixas para conviver com uma abordagem situacional;

- motivação e premiações baseadas nas metas externas avaliadas posteriormente, levando em conta o que de- 
veria ser feito. 0 objetivo dessa visão é reduzir o que os autores chamam de "jogo orçamentário", no sentido de atingir metas fixas a todo custo, inclusive abrindo mão de princípios éticos;

- processo estratégico contínuo, descentralizado e até mesmo local, que deve ser incentivado considerando o nível de ambição e respostas rápidas;

- oferecimento de recursos quando demandados, o que reduz perdas, desperdícios e gastos desnecessários, el iminando-se questões do tipo: "tenho que gastar para não perder a verba no ano que vem";

- coordenação entendida como "um time" ou "todos no mesmo barco", encorajando a cooperação e a excelência dos serviços;

- circulação rápida de informações, que devem ser disponibilizadas para facilitar o aprendizado e encorajar o comportamento ético.

Alguns princípios são oferecidos no desenvolvimento da proposta (Hope e Fraser, 2003, p. 70-92), cujos destaques são: a definição de metas práticas realizáveis relacionadas com melhorias, desconectadas da avaliação de desempen ho e premiações; a avaliação do desempenho e as premiações baseadas em contratos de melhorias relativas, levando em conta o que deveria ser feito, diferentemente da visão tradicional, que estabelece a priori a meta e posteriormente a compara com o resultado real; transformação do seu plano de ação numa sucessão de mel horias contínuas, inclusive os processos; disponibilização dos recursos quando necessários; coordenação de ações conjuntas na entidade de acordo com as demandas do cliente; controles baseados na governança efetiva e nos indicadores de desempenho relativos.

Ao se excluir o orçamento anual, que efeitos se verificam na gestão das organizações? No Quadro 1, Hope e Fraser $(2003$, p. 27) indicam, de maneira comparativa, al guns elementos da gestão que permitem entender o que muda de acordo com a proposta.

\section{OS BENEFÍCIOS DA ABORDAGEM BEYOND BUDGETING}

Hope e Fraser (2003) almejam que sua proposta possa atender às três críticas apresentadas. N esse sentido, apresentam três argumentos que defendem a abordagem beyond budgeting.

0 primeiro é referente a sua simplicidade, baixo custo e rel evância para os usuários. Os argumentos dos autores levam em conta: a) a gestão adaptativa e descentralizada, que proporciona autoridade e capacidade de decisões rápidas em seus mercados, gerando condições de resposta apropriada às demandas; b) 0 fato de não se desenvolver o orçamento anual implica uma redução de trabal ho e custo. Por outro lado, os profissionais envolvidos passam a dedicar seu tempo a atividades mais nobres, com mudança do foco do modelo, de centralizado em termos de controle para descentralizado para cada local. Dessa maneira, as equipes passam a se engajar no planejamento e controle; c) as lideranças são beneficiadas, pois passam a ter mais tempo para atividades de orientação do seu pessoal.

0 segundo argumento é referente ao tratamento dos fatores de êxito da economia da informação. Os autores consideram que 0 crescimento sustentável é direcionado pela "estratégia inovadora" com foco na a criação de valores de longo prazo. Para isso, dentre vários elementos importantes, é preciso dispor e manter os melhores profissionais, o que exige ações para avaliar suas capacidades criadoras. Isso terá maior probabilidade de sucesso num ambiente de liberdade e autonomia. A inovação contínua tem dificuldade de conviver com os orçamentos fixos, o que seria facilitado por um ambiente mais livre e criativo.

A demanda por redução de custos é permanente, e deveria vir não apenas de cima para baixo na estrutura das organizações, o que limita o seu potencial de abrangência. A expectativa é de que, uma vez envolvidas as demais camadas da hierarquia, os profissionais se sintam mais integrados à organização e tenham maiores compromissos com os resultados, buscando a redução de custos.

As necessidades dos clientes serão atendidas de maneira adequada, sem pressões para atingir metas, 0 que deve provocar mel horia no próprio relacionamento de longo prazo. Os relatórios devem ser estruturados de maneira ética. Esse aspecto é tratado dentro do encorajamento de boa governança e comportamento ético. A completa abertura para disponibilização de informações é parte crítica do processo.

0 terceiro argumento diz respeito ao encorajamento da boa governança e do comportamento ético. Parte do princípio de que as pessoas querem trabalhar nas e com as organizações mais virtuosas e esperam ter meIhor equilíbrio entre atividades profissionais e vida pessoal. Elas querem conhecer a situação atual e as perspectivas da empresa, e também querem confiar nas pessoas e ser parte de uma equipe. Entretanto, uma 
questão importante é que ainda nem todas as empresas atuam dessa forma. A ausência da pressão das metas fixas, na opinião dos autores, torna possível uma melhoria no comportamento ético. A abertura e transparência são peças-chave para a prática do encorajamento da boa governança.

\section{ANÁLISE COMPARATIVA}

A análise foi desenvolvida levando-se em conta as críticas que motivaram a proposta, a sua efetividade diante do processo de planejamento e os novos problemas provavelmente gerados pela abordagem beyond budgeting. As críticas podem ser segmentadas em três grupos: o papel do instrumento, a sua utilização inadequada e as limitações do instrumento.

\section{0 papel do instrumento}

0 papel do orçamento dentro do tripé planejamento estratégico, controle gerencial e controle operacional tem mudado, e o orçamento - no âmbito do controle gerencial - passou a ocupar espaço que antes não era devido nem cobrado. 0 crescimento do interesse em

Quadro 1 - Comparativo de elementos na gestão das empresas

\begin{tabular}{|l|l|}
\hline DESCRIÇÃO & \multicolumn{1}{|c|}{ ORÇAM ENTO TRADICIONAL } \\
\hline Metas & As metas são fixadas anualmente. \\
\hline $\begin{array}{l}\text { Premiações e } \\
\text { bonificações }\end{array}$ & $\begin{array}{l}\text { Os executivos recebem desde que se enqua- } \\
\text { drem nos objetivos das metas. }\end{array}$ \\
\hline Planos & $\begin{array}{l}\text { A figura das metas fixas (contratos fixos) está } \\
\text { relacionada aos planos. }\end{array}$ \\
\hline Recursos & $\begin{array}{l}\text { Os recursos cuja aceitação de disponibilida- } \\
\text { de para apoiar os orçamentos operacionais e } \\
\text { de capital são colocados à disposição }\end{array}$ \\
\hline Coordenação & $\begin{array}{l}\text { As atividades serão coordenadas com outros } \\
\text { gestores de planos de acordo com plano aceito } \\
\text { ou redirecionado por nível superior. }\end{array}$ \\
\hline Controles & $\begin{array}{l}\text { Odesempenho deve sermonitorado mensalmen- } \\
\text { te e qualquer variação significativa deve ser revi- } \\
\text { sada. Forecast demandado trimestralmente. }\end{array}$ \\
\hline
\end{tabular}

termos de manufatura e indicadores não monetários fez com que o instrumento fosse questionado e reposicionado nas empresas. Questionou-se a centralização, e sugeriram-se estilos mais participativos.

Por fim, o próprio questionamento da utilidade do planejamento estratégico trouxe conseqüências ao orçamento. Este último tópico pode ser tratado a partir da abordagem que considera que um plano estratégico adequadamente elaborado proporciona melhores condições de estruturação de um bom orçamento, sendo o inverso também verdadeiro. Os aspectos mais relevantes são três.

0 primeiro é 0 aspecto da separação entre o planejamento e a execução. Essa crítica está relacionada com situações em que o orçamento é definido por outrem, que não o gestor, que vai fazer com que as metas sejam atingidas. Em alguma dimensão isso não deveria acontecer pelo processo clássico, a partir da participação dos agentes.

0 segundo aspecto é a falha ao tratar as variáveis fundamentais da competitividade. Essa crítica pode ser ol hada de várias maneiras, dentre as quais a que considera que os executivos devam perseguir metas com referências externas, ligadas à concorrência e ao mer-

\section{BEYOND BUDGETING}

As metas não são fixas, mas continuamente monitoradas contra um dado benchmarking, preferencialmente externo, negociado com o grupo de gestores.

Existe a confiança do recebimento da premiação a partir da avaliação do grupo de gestores que analisa o desempenho na abordagem "daquilo que deveria ser feito".

Existe a confiança de que qualquer ação possa ser exigida para atingir metas de médio prazo aceitas pelo grupo de gestão, dentro dos princípios de governança e parâmetros estratégicos da entidade.

Existe a confiança de prover os recursos quando forem necessários.

Existe a delegação de confiança para que 0 gestor coordene as atividades a partir de acordos periódicos e exigências de clientes.

Existe confiança de que o forecast seja baseado na alternativa mais provável, de maneira que só existirá interferência se a tendência dos indicadores ficar fora de certos parâmetros. 
cado. N esse sentido, o argumento não deveria ser válido, pois tanto a forma de estruturar as variáveis como a intensidade de desafio serão decisões dos gestores, e não uma limitação ou um impedimento da ferramenta.

Final mente, o terceiro aspecto é o pouco valor agregado à entidade, ou o fato de o orçamento ser ou não uma perda de tempo. Este ponto não foi tratado de maneira sistemática e metodológica pelos autores. 0 que pode significar não agregar valor? A inexistência de um instrumento pode provocar perda de negócios, dificuldades financeiras e não otimização de resultados. Um instrumento gerencial é, em si, uma ferramenta, um meio para que as ações sejam desenvolvidas. Se fosse possível viver sem eles, a gestão se tornaria mais fácil e menos custosa.

\section{Utilização inadequada do instrumento}

Sobre a utilização inadequada, os autores levam em conta que os aspectos mencionados estão relacionados à forma como os gestores querem utilizar o instrumento. Os aspectos mais rel evantes são mencionados a seguir.

Primeiramente, tanto o fato de superestimar quanto subestimar o instrumento está sempre presente na sua elaboração. Isso pode ocorrer tanto por interesse do agente em proteger-se como nas questões ligadas à incerteza ou mesmo à etapa do aprendizado. Os clássicos recomendam o feedback como uma das formas de, ao longo do tempo, se implementarem mel horias nesse tipo de distorção. A prática de revisões do orçamento anual também é uma das formas possíveis de tratar essa questão, muito embora tais revisões possam ser percebidas como "aberturas parciais" para mudanças.

Em segundo lugar, há o fenômeno da pseudoparticipação dos agentes. 0 interesse variável dos gestores em participar é algo que faz parte da mescla cultural da organização, constituindo um ingrediente compulsório para o desenvolvimento de qualquer tipo de instrumento gerencial. Existem organizações com dezenas de milhares de funcionários. Nesses casos, como assegurar a participação? U ma das respostas é discutir o sentido da palavra participação dentro de um contexto de maior flexibilidade. Nessa linha de raciocínio, ser chamado para discutir, para oferecer alternativas e receber informações são possibilidades de distintos graus de participação. Dessa maneira, o que se espera é um efetivo envolvimento, que pode ser obtido de várias maneiras, mesmo com uma meta anual estável. Qualquer que seja o modelo utilizado, o tom do agente decisório será fundamental para viabilizar a participação dos gestores.
Em terceiro lugar, há a questão do foco na redução de custos e não na criação de valores. $N$ a verdade, trata-se de uma limitação da visão dos gestores com relação ao modelo. Este pode ser utilizado tanto para uma das visões como para as duas, à medida que direciona e proporciona uma visão de resultado. U ma meta não definida por ocasião do orçamento anual e posteriormente percebida como adequada deveria ser incorporada ao instrumento, e o inverso também deveria ser considerado. Ao menos essa é a perspectiva de Welsch, Hilton e Gordon (1988).

Em quarto lugar, podem se sufocar as iniciativas. Um instrumento gerencial sem uma perspectiva pode ter essa conseqüência, seja o orçamento tradicional ou beyond budgeting. Em outras palavras, 0 grau de abertura e envolvimento em momentos de revisão de metas é o que define o potencial de flexibilidade e criatividade permitido pela gestão do instrumento.

Em quinto lugar, há a questão da coordenação centralizada do processo de planejamento, em que se propõe uma descentralização, inclusive na implementação. Mas a descentralização implica diretrizes básicas desse processo de coordenação para que a otimização dos esforços ocorra no horizonte temporal contemplado. Em algumas empresas, o processo de planejamento não pode ser tão flexibilizado por conta de sua complexidade e de seu porte. Uma crítica feita ao orçamento denominado centralizado considera que os participantes não têm o poder para definir suas metas. Essa visão é distorcida, pois a participação é um ingrediente previsto e importante para a organização.

Em relação ao sexto aspecto, há o problema do eventual comportamento disfuncional dos gestores. Os autores chegam a citar a Enron e a WorldCom como exemplos de situações provocadas pelo orçamento fixo, uma vez que as pessoas, tendo que atuar para obter resultados, podem adotar conduta antiética. Essa argumentação carece de maior estruturação e constatação empírica, pois, para ser válida, precisariam ser analisadas situações de empresas com problemas de ordem ética e que foram gerenciadas de maneira extremamente flexível e participativa. A ética transcende o instrumento, e sua utilização inadequada deve ser buscada no universo ético da gestão.

$E$, finalmente, pressupõe-se a ausência de confiança, o que ocorre quando se definem metas de longo prazo. Existisse confiança, não seria necessário definir metas a priori. Essa afirmação é delicada e carece de maior profundidade de pesquisa. Ao contrário, pode-se afirmar que as pessoas nem pensariam em 
negociar e definir metas se não houvesse prévia confiança entre os agentes. Por outro lado, a coordenação das atividades exige que os gestores coordenem as decisões, o que requer a definição a priori.

\section{Limitação do instrumento}

Dentre as limitações do instrumento, pode-se destacar que, primeiramente, trata-se de um instrumento custoso. 0 custo de um instrumento gerencial é algo relativamente fácil de apurar, podendo incorporar níveis variados de precisão e abrangência e critérios de abstração. A pesar disso, o benefício é menos tangível e pode ser analisado do ponto de vista tanto de quanto se ganha como pela perspectiva de quanto custaria a inexistência do orçamento. Ambas foram ignoradas pelos autores que questionam o orçamento anual.

0 segundo ponto é a questão da alocação de custos (considerados não negociáveis). A existência de critérios de alocação de gastos por áreas de negócios, centros de resultados e de custos faz parte da visão de controle, e, como decorrência, os preços de transferência são apurados. Alguns estudiosos não se conformam com os resultados e o controle necessários em um dado tipo de procedimento. Esse problema vai existir qualquer que seja a forma de encarar o orçamento. Trata-se de uma questão filosófica de atribuir custos e de aplicar o controle.

0 terceiro ponto é a questão de a média gerência insistir em controlar e comandar. Essa perspectiva é necessária, pois a abordagem de planejamento e controle faz parte de um todo em que 0 acompanhamento do desempenho das variáveis críticas é parte da abordagem que pretende assegurar o resultado pretendido. Alguém que não o próprio gestor tem que fazer isso. É muito difícil evitar tal comportamento num ambiente em que 0 autocontrole é exigido das áreas e pessoas, mas avança ainda muito lentamente.

0 quarto ponto é em relação ao processo orçamentário, que não encoraja as pessoas ao desempenho, mas a executar 0 orçamento. Desde que seja flexível e revisado, encoraja a existência de um padrão que contemple os desafios e seja realista. Pode incentivar um senso de justiça nas pessoas envolvidas. $\mathrm{Na}$ verdade, $\mathrm{O}$ ponto não é o orçamento em si, mas como é utilizado. Sendo bem elaborado, encoraja o gestor ao desempenho, e é algo útil, pois elimina a ambiguidade, tornando claro o que se pretende.

Finalmente, a revisão do orçamento toma tempo, e as empresas não conseguem fazê-la rapidamente. Essa é uma questão que não deixa de ser curiosa, pois o tempo e os recursos necessários para desenvolver o instrumento, dependendo da complexidade da organização, do modelo cultural do gestor e do tipo de mudanças verificadas, podem ser otimizados ( 0 tempo e os recursos) se o planejamento e os compromissos forem definidos a priori. Ao mesmo tempo em que os autores se preocupam em mensurar quanto gastam, em termos de tempo, com o processo, deixam de apurar quanto economizam ao desenvolvê-lo, o que proporciona uma visão apenas parcial da questão.

\section{CONSIDERAÇÕES FINAIS}

$\mathrm{N}$ ão deixa de ser interessante perceber o quanto as tendências de interpretação de um tema podem ser díspares. De um lado, uma abordagem que, embora percebendo limitações e imperfeições, pretende instrumentalizar, medir, buscar compromissos e controlar, enfim aperfeiçoar um modelo existente; e, de outro, a perspectiva oposta, de Hope e F raser, pregando a eliminação do instrumento que se propõe implementar as estratégias da organização. Aparentemente tais visões decorrem de diferentes percepções que os autores possam ter das entidades e de seus executivos. Dessa maneira, respondendo a questão de pesquisa, fica evidente que os problemas citados pela abordagem beyond budgeting não são novos ou ignorados pelos autores clássicos que trataram o tema anteriormente. Ao contrário, são previstos e mencionados na literatura. Percebe-se que o foco da gestão na abordagem beyond budgeting está no gestor, na sua flexibilização. Conseqüentemente, para que o modelo escoIhido para a organização tenha êxito, será necessário treinar um conjunto de pessoas com habilidades para administrar sem o orçamento. A operacional ização da abordagem flexível, com o uso do instrumento orçamentário, pode compatibilizar mais facilmente as necessidades da organização sem criar novos riscos, inerentes ao excesso de flexibilidade criado pela abordagem ora proposta.

É importante registrar que muitas vezes os problemas decorrem da má utilização do instrumento, e as soluções propostas por Hope e Fraser passam por recomendações já tratadas pelos autores clássicos. 0 que poderia ser um aspecto significativo mas, no momento, não reforça a abordagem é o fato de se verificar a insipiência do tratamento empírico oferecido pelos autores quando se trata de constatações de resultados que não sejam localizados em algumas empresas, na 
forma de casos, o que até pode ser considerado normal, dado o estado da arte.

Alguns problemas relacionados pelos autores clássicos não foram tratados por Hope e Fraser. Dentre eles, podem se destacar: o controle, no seu sentido original, pode ser entendido como algo não desejável na entidade? Como coordenar o longo e o curto prazo numa organização sem um orçamento anual? Como saber se o desempenho está dentro do esperado na perspectiva dos investidores? Como corrigir o curso de uma ação se não forem definidos padrões? 0 compromisso dos gestores em atingir a meta passa a ser apenas uma demonstração de boa vontade?

Hope e Fraser (2003, p. xviii) consideram que 0 contrato fixo de desempenho, com variáveis fora do seu controle, leva o gestor a um comportamento indesejável e, muitas vezes, antiético. 0 que se pode concluir da análise da proposta dos autores é que a utilização inadequada do instrumento não deveria levar ao seu abandono. Principalmente porque uma parcela razoável das imperfeições citadas foi prevista pelos autores clássicos sobre orçamento empresarial, e foram prescritas ações que podem proporcionar sua eliminação ou minimização, muitas delas utilizadas na proposta do beyond budgeting. 0 s autores reconhecem isso, mas percebem o orçamento como um vírus que deve provocar todas as crises mencionadas. Assim, essa abordagem apenas aparenta ser radical, mas ignora os novos problemas gerados por sua proposta.

Como sugestões de temas para futuras pesquisas, seriam relevantes estudos empíricos sobre a utilização do beyond budgeting no Brasil, a análise de empresas que utilizam abordagens semelhantes, bem como a identificação de seu grau de satisfação alcançado ao longo do tempo.
NOTA

0 autor agradece 0 apoio do CN Pq e da Fipecafi ao projeto que originou este trabalho.

\section{REFERÊNCIAS BIBLIOGRÁFICAS}

FISHER, L. Onestep beyond. Accountancy, v. 129, n. 1303, p. 32-34, 2002.

HANSEN, D. R.; MOWEN, M. M. Cost M anagement: Accounting and Control. Cincinatti: South Western, 1996.

HANSEN, S. C.; OTLEY, D. T.; VAN DER STEDE, W. Practice developments in budgeting: an overview and research perspective. Journal of M anagement Accounting Research, v. 15, p. 95-116, 2003.

HOPE, J. Beyond budgeting: pathways to the emerging model. Balanced Scorecard Report. Harvard Business School Publishing, p. 3-5, 2000.

HOPE, J.; FRASER, R. Beyond Budgeting: How Managers Can Break Free from the Annual Performance Trap. Boston: Harvard Business School Press, 2003.

HORNGREN, C.; FOSTER, G.; DATAR, S. Cost Accounting: A Managerial Emphasis. Upper Saddle River, NJ: Prentice Hall, 1999.

KAPLAN, R. S.; NORTON, D. P. Balanced Scorecard: Translating Strategy into Action. Boston: Harvard Business School Press, 1996.

OTLEY, D. Management control in contemporary organizations: towards a wider framework. M anagement Accounting Review, v. 5, p. 289-299, 1994.

SCAPENS, R. W. N ever mind the gap: towards an institutional perspective on management accounting practice. M anagement Accounting Review, v. 5, p. 301-321, 1994.

STEINER, G. A. Strategic Planning: What Every Manager Must Know. New York: Free Press, 1979.

WELSCH, G.; HILTON, R.; GORDON, P. N ., Budgeting: Profit Planning and Control. $5^{\text {th }}$ ed., Englewood Cliffs, NJ: Prentice-Hall, 1988.

\title{
Artigo recebido em 07.08.2004. Aprovado em 28.02.2005.
}

\author{
Fábio Frezatti \\ Professor da FEA-USP. Doutor em Controladoria e Contabilidade pela FEA-USP. \\ Interesses de pesquisa nas áreas de contabilidade gerencial e controladoria, com dedicação \\ especial à existência dos artefatos, seus sucessos e fracassos em termos de implementação \\ e uso. Outros interesses: teoria institucional, teoria da contingência e comportamental. \\ E-mail: frezatti@usp.br \\ Endereço: Rua Joaquim Távora, 1020, Vila Mariana, São Paulo - SP, 04015-012.
}

